\title{
Home equity, mobility, and macroeconomic fluctuations
}

\author{
Vincent Sterk \\ University College London, United Kingdom
}

\section{A R T I C L E I N F O}

\section{Article history:}

Received 23 April 2014

Received in revised form

16 April 2015

Accepted 21 April 2015

Available online 4 May 2015

Keywords:

Housing markets

Labor markets

Refinancing constraints

DSGE

\begin{abstract}
A B S T R A C T
How does a fall in house prices affect real activity? This paper presents a tractable business cycle model in which a decline in house prices reduces geographical mobility, creating distortions in the labor market. This happens because homeowners face declines in their home equity levels, which makes it more difficult to provide the downpayment required for a new mortgage loan. Therefore, unemployed homeowners more often turn down job offers that would require them to move. The model can account for joint cyclical patterns in housing and labor market aggregates, and predicts a breakdown of the Beveridge curve in 2009. Counterfactual experiments are used to quantify the macroeconomic importance of the mobility channel during the Great Recession.

(C) 2015 The Author. Published by Elsevier B.V. This is an open access article under the CC BY license (http://creativecommons.org/licenses/by/4.0/).
\end{abstract}

\section{Introduction}

During the "Great Recession" of 2008, the U.S. economy experienced unusual disruptions in both housing and labor markets. Housing markets were hit by sharp declines in both prices and the number of transactions. Labor markets witnessed an increase in aggregate unemployment that was surprisingly large, even given the strong decline in job vacancies (Elsby et al., 2010). The upper panel of Fig. 1 plots vacancies versus the unemployment rate. The figure shows that the historically strong and negative correlation between these two variables, known as the Beveridge Curve, broke down during 2009. A common interpretation of this phenomenon is that frictions in the labor market had become more severe, causing unemployed workers and firms to be matched less efficiently. The simultaneous bust in house prices suggests that the reduction in labor market efficiency may have been related to problems in the housing market.

This paper explores the link between housing and labor markets over the business cycle from a macro perspective. I study cyclical patterns in U.S. data spanning four decades and document that busts in the housing market are associated with downturns in the labor market. Additionally, I construct state-level measures of labor market efficiency and show that during the Great Recession, states with more low-equity homeowners experienced greater declines in labor market efficiency.

To interpret these findings, I develop a parsimonious Dynamic and Stochastic General Equilibrium (DSGE) model in which house prices affect unemployment through a geographical mobility channel. When house prices decline, borrowingconstrained homeowners face difficulties in moving to a new house, reducing their incentives to accept job offers that are not within commutable distances from their current homes. As a consequence, a decline in house prices causes unemployment to rise and output to fall, which in turn feeds back into house prices.

I calibrate the model and show that it can account for much of the observed cyclical co-movements in housing and labor market variables. Moreover, based on only house price and output data, the model generates for 2009 a flattening of the Beveridge Curve, like in the data. That said, joint fluctuations in housing and labor markets do not fully derive from causal

E-mail address: v.sterk@ucl.ac.uk 

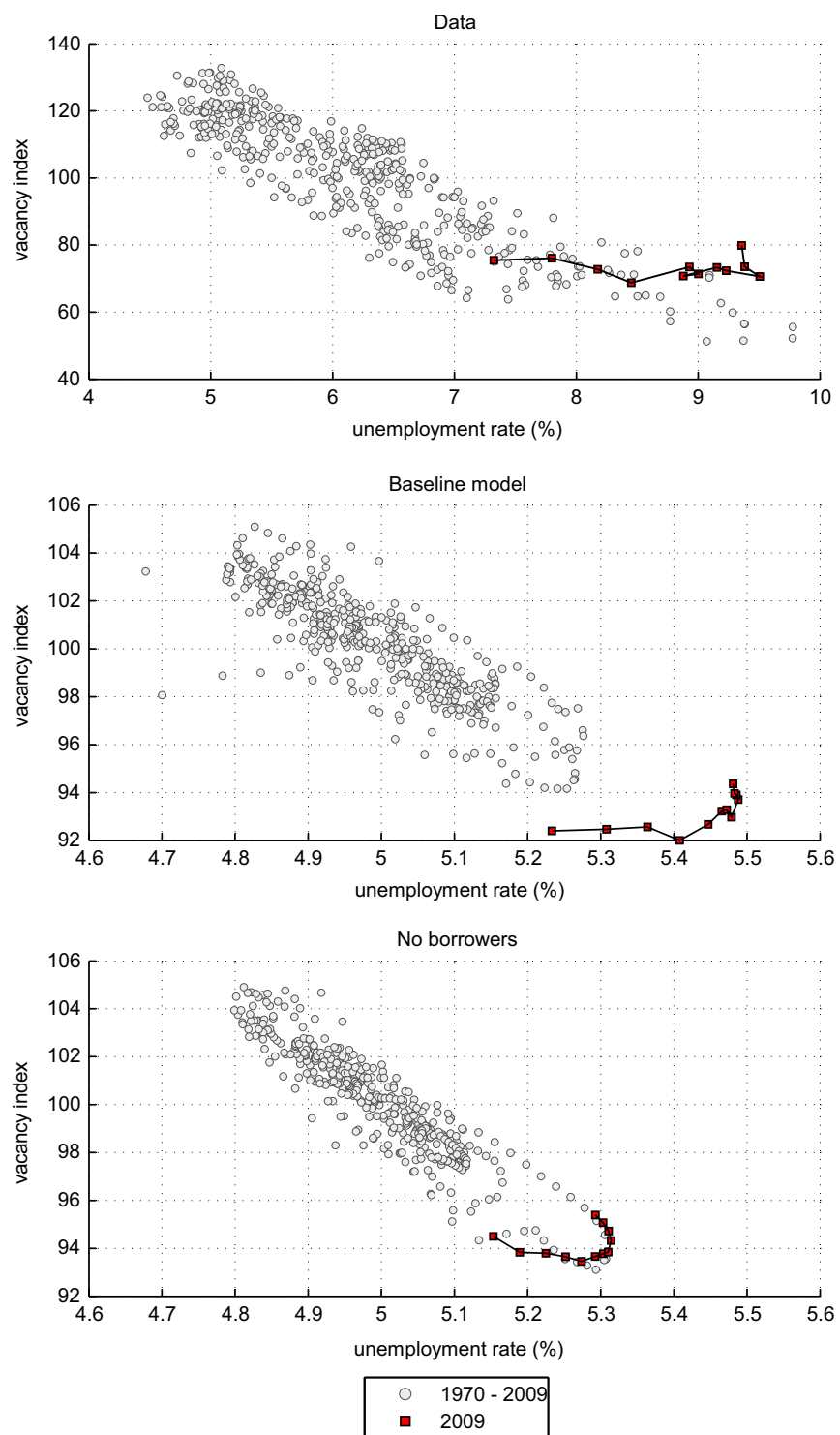

Fig. 1. Beveridge curve in the data, in the baseline model and in the model without borrowers. Notes: observations are monthly and cover the period from January 1970 until December 2009. All variables were logged and HP-filtered with smoothing parameter value $81 \cdot 10^{5}$. This value corresponds to the one used by Shimer (2005) for quarterly data, but is adjusted for the frequency using the factor recommended by Ravn and Uhlig (2002). After filtering, levels were re-constructed by adding either the average of the trend component over the sample (for the data) or the steady-state level (for the model). Data source unemployment rate: U.S. Department of Labor. Data source vacancy index: (Barnichon, 2010).

spillovers due to the mobility channel. The quantitative importance of such spillovers is strongly disciplined by model parameters, in particular parameters that pin down the fraction of households that is credit-constrained. Simple counterfactual experiments are used to isolate the effect of a fall in house prices on mobility and other macro-outcomes.

The model is able to reproduce the positive co-movement between house prices and transactions observed in the data, due to the presence of a refinancing constraint that is new to DSGE models. ${ }^{1}$ A standard modeling choice is to assume that collateral constraints tie the amount of debt to the value of the underlying housing collateral, and that in each period mortgagors are required to refinance their loans (see e.g. Iacoviello, 2005). The unrealistic implication of these assumptions is that fluctuations in house prices affect the borrowing limits of all homeowners during each period. By contrast, my constraint only requires those who move to a new house to refinance their loans, so households can shield their borrowing capacity from a fall in house prices by staying in their current locations, avoiding the need to take out a new mortgage loan.

${ }^{1}$ Stein (1995) considers a similar constraint and shows that it can generate positive co-movement between house prices and transaction volumes in a very stylized three-period model. The advantage of my constraint is that it is easily embedded in a DSGE framework that can be solved using standard techniques. 
After a decline in housing wealth, it becomes harder to provide the downpayment for a new loan, reducing incentives to move.

Fluctuations in mobility affect real activity through their effects on the efficiency of the labor market. The matching process between unemployed workers and firms is modeled following a standard version of the Diamond-MortensenPissarides model, but with the addition that some job offers can only be accepted if the worker moves to a new location. When there are barriers to mobility due to a fall in house prices, more job offers are turned down. Thus, the economy enters a period during which, for a given level of vacancies, the unemployment rate is higher than during normal times. An interesting prediction of the model is that the mobility effects persist beyond the decline in house prices.

The model in this paper is the first that enables the analysis of the dynamic effects of house prices on mobility, as well as the spillovers to the labor market and real activity. Head and Lloyd-Ellis (2012) and Rupert and Wasmer (2012) have developed models with mobility effects to study the role of housing markets in determining long-run unemployment rates. However, their models are less suited to study aggregate fluctuations because solving stochastic versions of their models would be very challenging. By contrast, my model can be easily solved using standard methods. ${ }^{2}$ I use the model to study the drivers behind economy-wide fluctuations in housing and labor markets rather than regional shocks, as analyzed by Karahan and Rhee (2013) and Nenov (2013).

Understanding the causes of a spike in unemployment is important for a government deciding on various policy measures, including monetary and fiscal stabilization policies. It is therefore not surprising that the " house lock" hypothesis has been the topic of several micro-econometric studies. Various findings are consistent with the idea that a decline in house prices impedes labor mobility (Henley, 1998; Chan, 2001; Engelhardt, 2003; Ferreira et al., 2010). However, several recent empirical studies have been sceptical about the importance of the mobility channel for macro outcomes (see e.g. Valletta, 2015; Schulhofer-Wohl, 2012; Molloy et al., 2011; Farber, 2012). ${ }^{3}$ By itself, the idea that a decline in house prices can discourage some borrowing-constrained homeowners from moving seems uncontroversial. However, the key question is whether this can be a main determinant of overall unemployment. The model presented in this paper provides a simple but coherent macro framework to address this quantitative question. For the Great Recession period, I find that the drop in house prices can account for an increase in the unemployment rate of up to 0.6 percentage points.

The remainder of this paper is organized as follows. Section 2 discusses empirical evidence. Section 3 describes the theoretical model. The predictions of the model are presented and compared to the data in Section 4 . Section 5 concludes.

\section{Empirical evidence}

\subsection{Cyclical fluctuations in housing and labor markets}

I document the joint behavior of aggregate housing and labor market variables, based on a quarterly data sample over the period 1970:1-2009:4 for the U.S. The housing market variables are the real house price and home sales, as reported by the National Association of Realtors. The house price is the median sales price of existing single-family homes, deflated by the consumer price index. Home sales are measured by the number of existing single-family homes sold in a particular month. ${ }^{4}$ The reason for analyzing home sales is that this series can be expected to be a good proxy for overall mobility among homeowners. ${ }^{5}$ The labor market variables are unemployment, vacancies, and the unemployment outflow hazard. Unemployment is measured by the civilian unemployment rate as released by the U.S. Department of Labor. Vacancies are measured by the Help Wanted Index, released by the Conference Board. To account for the rise in Internet vacancies, I use the adjusted series as constructed by Barnichon (2010) for the post 1995 period. The quarterly unemployment outflow hazard is constructed following Shimer, $2007{ }^{6}$

Raw data: Panels A and B of Fig. 2 display the real house price and the number of home sales, respectively, for the period since 1970. Both variables are upward trending and display cyclical fluctuations. Two major boom-bust episodes in home sales stand out. The first boom began around 1975 and was associated with a run-up in house prices. The subsequent bust in the number of home sales started around the time Paul Volcker initiated his disinflationary monetary policy, and was

\footnotetext{
${ }^{2}$ Business cycle models that are related to my model include those of Iacoviello and Pavan (2013), who model borrowing constraints and infrequent housing adjustments, but not matching frictions in the labor market, and of Andres et al. (2011), who analyze a model with frictions in labor and credit markets, but without mobility effects.

${ }^{3}$ A notable exception is Goetz (2013) who makes use of an exceptionally detailed data set. In particular, he links data from the American Community Survey and the Longitudinal Employer-Household Dynamics, enabling him to observe which workers take on a new job in another Metropolitan Statistica Area (MSA). He finds that homeowners who experienced a decline in their home values are 20 percent less likely to accept a new job outside their current MSA.

${ }^{4}$ Monthly series on house prices and the number of home sales were converted into quarterly series by taking simple averages.

5 The main alternative to the home sales index would be the mobility measures constructed from the Current Population Survey (CPS), which distinguish between owners and renters, but are released on a yearly frequency only. This severely limits the information content of these data, especially when constructing business cycle statistics. However, according to CPS data the mobility rate among homeowners fell 30 percent during the period $2005-$ 2009, which is very similar to drop in the home sales during the same period.

${ }^{6}$ Shimer (2007) modifies the series to adjust for a structural break in January 1994, caused by a change in CPS methodology. I would like to thank Ayşegül Şahin for sharing the adjusted series.
} 
A

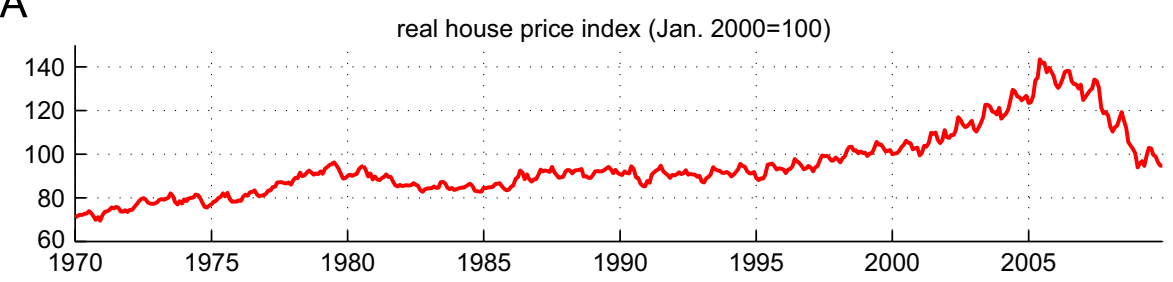

B

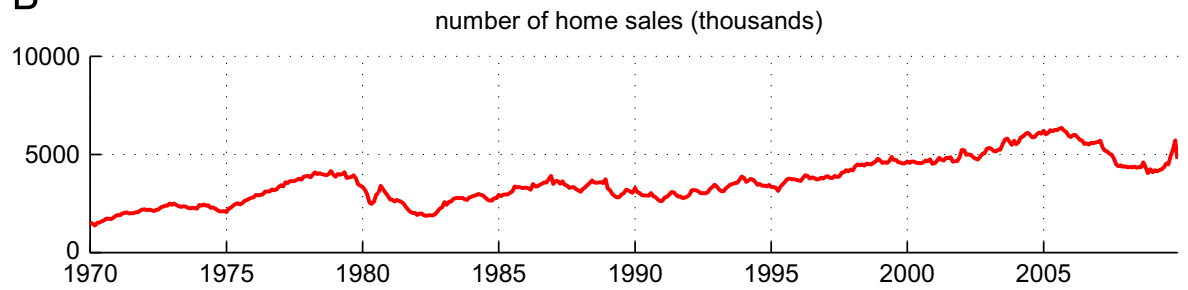

C

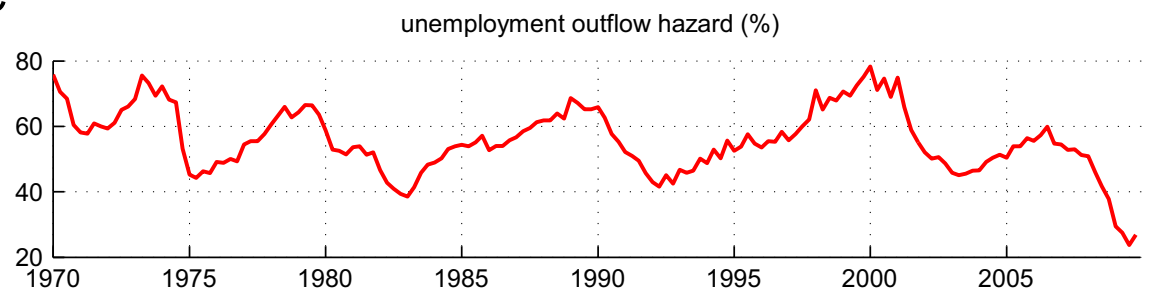

D

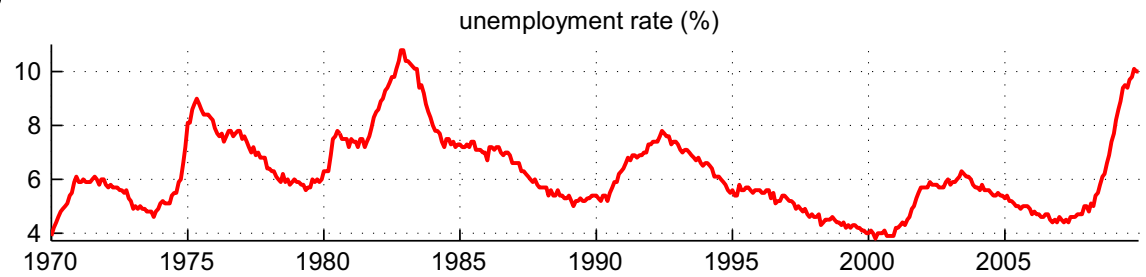

E

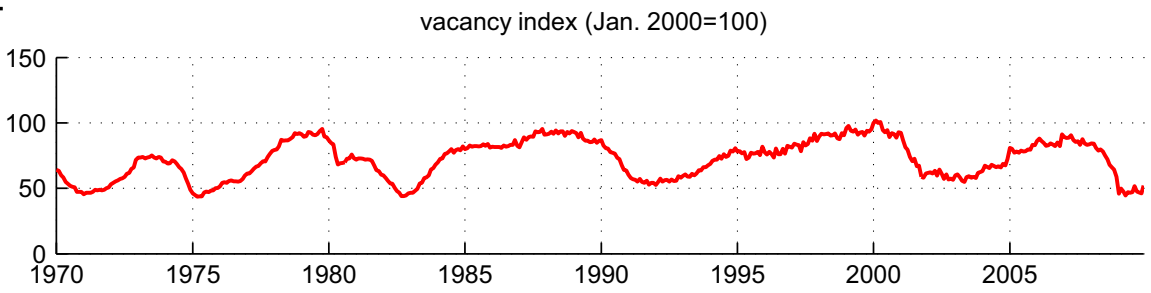

Fig. 2. Raw data series. Notes: Quarterly observations. Monthly series for house prices, home sales, the unemployment rate and the vacancy index were converted into quarterly series by simple averaging. Sources: see text.

accompanied by a moderate decline in house prices. The second boom seems to have started around the year 2000, and resulted in a bust that started around 2005 . $^{7}$

The unemployment outflow hazard, the unemployment rate and the vacancy index are plotted in panels C, D, and E of Fig. 2, respectively. The cyclical fluctuations in these variables seem closely related to those in home sales during several episodes. An exception is the period from 2001 until 2004, when home sales increased but the outflow hazard fell. The unemployment rate reached its highest level during the two housing busts discussed above, and the increase in the unemployment rate during recent years was particularly sharp. Note that during the run-up in unemployment in the last

\footnotetext{
${ }^{7}$ At the very end of the sample, there is a brief spike in home sales, which seems related to the Home Buyer Tax Credit program, which applied to homes purchased between January 1, 2009 and May 1, 2010.
} 
Table 1

Standard deviations and correlations: data and baseline model.

\begin{tabular}{|c|c|c|c|c|}
\hline & House pr. $\left(p_{h}\right)$ & Home sales $\left(n_{m}\right)$ & $u$ rate $\left(n_{u}\right)$ & Vacancies $(v)$ \\
\hline \multicolumn{5}{|l|}{ A. Data } \\
\hline Std. dev. relative to output & 2.72 & 6.65 & 7.28 & 8.18 \\
\hline Correlation with $n_{u}$ & -0.44 & -0.33 & 1.00 & -0.90 \\
\hline Correlation with $p_{h}$ & 1.00 & 0.55 & -0.43 & 0.40 \\
\hline \multicolumn{5}{|l|}{ B. Model: baseline } \\
\hline Std. dev. relative to output & 2.94 & 7.00 & 1.22 & 1.06 \\
\hline Correlation with $n_{u}$ & -0.62 & -0.57 & 1.00 & -0.87 \\
\hline Correlation with $p_{h}$ & 1.00 & 0.51 & -0.62 & 0.52 \\
\hline \multicolumn{5}{|l|}{ C. Model: only TFP shocks } \\
\hline Std. dev. relative to output & 1.08 & 2.74 & 1.20 & 1.05 \\
\hline Correlation with $n_{u}$ & -0.97 & -0.98 & 1.00 & -0.92 \\
\hline Correlation with $p_{h}$ & 1.00 & 0.98 & -0.97 & 0.98 \\
\hline
\end{tabular}

Notes: Data in Panel A are quarterly and are logged and HP-detrended with smoothing parameter value $10^{5}$, following Shimer (2005). Model-simulations in Panel B and Panel C are monthly and are logged and HP-detrended with smoothing parameter value $81 \cdot 10^{5}$. This value corresponds to the one used for quarterly data, but is adjusted for the frequency using the factor recommended by Ravn and Uhlig (2002).

year of the sample, vacancies no longer declined. The unemployment outflow hazard, however, declined to a level that is by far the lowest in the sample.

Cyclical patterns: Statistics describing the cyclical properties of the series are displayed in the upper panel of Table 1 , which reports the volatilities of the real house price, home sales, the unemployment rate, and vacancies, relative to the volatility of real GDP. House prices are substantially more volatile than GDP. In turn, home sales, the unemployment rate and vacancies are much more volatile than the real house price. Table 1 also displays the correlations of the aforementioned variables with the unemployment rate and with the real house price. The unemployment rate and vacancies are negatively correlated with the real house price. Also, there is a positive correlation between the real house price and the number of home sales. These patterns are consistent with the proposed mobility channel.

In online Appendix A, I study responses to housing market shocks using a structural VectorAutoRegression (VAR). A negative shock to the housing market, associated with a decline in house prices and the number of home sales, leads to a reduction in the unemployment outflow hazard, vacancies and real GDP, and to an increase in unemployment.

\subsection{State-level evidence}

Within the U.S., there has been large variation in the extent to which individual states were exposed to a housing market boom and bust during the 2000s. ${ }^{8}$ The proposed mobility channel predicts specifically that labor market efficiency deteriorates more strongly in states with larger housing slumps.

To construct a state-level measure of labor market efficiency, I assume that in each state unemployed workers and firms are matched according to a function of the form $m=\mu n_{u}^{\eta} v^{1-\eta}$, where $m$ is the number of new worker-firm matches, $n_{u}$ is the unemployment rate, $v$ is the number of vacancies, $\eta$ is the matching function elasticity and $\mu$ captures the efficiency of the matching process. An empirical measure of matching efficiency can be constructed by evaluating the right-hand side of the equation $\ln \mu=\ln m-\eta \ln n_{u}-(1-\eta) \ln v .^{9}$ For this purpose I use state-level data on unemployment, the number of hires and vacancy postings, obtained, respectively, from the Local Area Unemployment statistics, the Quarterly Workforce Indicators, and the Conference Board's vacancy data set. The matching elasticity parameter $\eta$ is set to $0.5{ }^{10}$

I correlate the change in state-level match efficiency between 2007 and 2011 with the state-level share of mortgages with equity levels lower than five percent, as reported by Corelogic for the fourth quarter of 2011. The latter variable is used as a proxy for the fraction of households with low levels of home equity. The two variables are negatively correlated with a coefficient of -0.42 , which is highly significant (the $p$-value is 0.006$)$. An even stronger negative correlation $(-0.47)$ is obtained when increasing the matching function elasticity $\eta$ to 0.7 , the upper bound of the range considered plausible. Thus, in states in which low home equity became most prevalent after the downturn in the housing market, the efficiency of the labor market matching process deteriorated particularly strongly. ${ }^{11}$

\footnotetext{
${ }^{8}$ The "sand states" Arizona, Nevada and Florida have been hit notoriously hard by the collapse of the housing market around 2007. In other housing markets, such as those of New York and Pennsylvania, the downturn has been relatively modest.

${ }^{9}$ For a more extensive analysis of matching efficiency over the business cycle see Sedláček (2014).

${ }^{10}$ According to Petrongolo and Pissarides (2001), plausible values for $\eta$ are between 0.5 and 0.7 . Running a simple OLS regression of the log outflow hazard on a constant and the log of the vacancy-unemployment ratio results in an estimate for $\eta$ of 0.57 .

${ }^{11}$ See online Appendix A for a plot of the data, which are available for 43 states. The relation is robust to using a more sophisticated measure of matching efficiency, developed by Barnichon and Figura (2011), which accounts for variations in sectoral composition. Using this alternative measure the correlation is very similar $(-0.37)$
} 


\section{General equilibrium model}

This section presents the theoretical model, which is kept stylized for simplicity. Three key ingredients allow the model to capture the essence of the geographical mobility channel that I set out to study. First, agents are geographically mobile, in a very simple sense. Mobility decisions are integrated into their intertemporal optimization problems and are affected by both aggregate and individual conditions.

The second ingredient is a financial friction on the side of households, which takes the form of a collateral constraint, in the spirit of Kiyotaki and Moore (1997), Iacoviello (2005) and Favilukis et al. (2012). A key innovation of my model is that collateral requirements apply only to new mortgages, which are taken out when a borrower moves. For existing mortgages, debt is simply limited not to exceed the amount of the previous period. ${ }^{12}$ This feature generates a decline in mobility when house prices fall. Consider for example a decline in house prices that is so large that borrowers' home equity levels shrink to zero. Without wealth, it becomes nearly impossible to provide the downpayment required for a new mortgage loan. However, as long as a borrower does not move, she can sustain her old mortgage loan. This makes moving relatively unattractive. ${ }^{13}$

The final main ingredient of the model is a friction in the labor market. As in Pissarides (2000), unemployed agents search for vacancies and occasionally receive a job offer. But a fraction of those job offers can only be accepted if the agent moves, as commuting would be infeasible.

\subsection{Model description}

The model economy is populated by a continuum of households of unit mass who consume housing and non-durables. There are two types of households: impatient and patient households. In equilibrium, the impatient households borrow from the patient ones, but borrowing is restricted by a refinancing constraint. Each of the two representative households consists of a continuum of members, who are either employed or unemployed. ${ }^{14}$ In each period, a certain fraction of the members moves and the household pays a fixed moving cost for each of those members. The desire to move depends on the degree of satisfaction of a member with their current location, which is idiosyncratic and stochastic. Moving costs are only worth paying for those members who are sufficiently dissatisfied with their current locations.

Employment relationships are destroyed at an exogenous rate, after production has taken place during the period. A member whose job gets destroyed in period $t$ can search for a job in the same period and may have a new job in period $t+1$ without becoming unproductive. If not, the member becomes unemployed in period $t+1$ and continues searching. The total number of meetings between workers and firms is determined by a standard matching function, which depends on the aggregate number of job searchers and the number of vacancies. However, a fixed fraction of all meetings can only result in a productive relationship if the member moves. This captures job offers from regions other than the one in which the worker resides. ${ }^{15}$ When moving is sufficiently unattractive, the job offer is turned down and the member remains unemployed.

To impatient households, there is one additional factor affecting mobility decisions, namely the effect on the borrowing capacity of the household. The fraction of debt that the household has to refinance is equal to the fraction of its members moving to a new location. After a fall in house prices, refinancing becomes unattractive, which creates a barrier to geographical mobility.

\subsubsection{Impatient households}

Let $E_{t}$ denote the conditional expectations operator. The impatient households maximize the following objective function:

$$
E_{0} \sum_{t=0}^{\infty} \beta^{t}\left\{\ln c_{t}+\alpha z_{h, t} \ln h_{t}+\kappa n_{u, t}+u_{l o, t}\right\},
$$

where $\beta$ is their discount factor, $c_{t}$ is non-durable consumption, $h_{t}$ is the stock of housing, $\alpha$ is a housing preference parameter, $z_{h, t}$ is a housing preference shock, $n_{u, t}$ is the fraction of unemployed members, each generating a utility flow $\kappa^{16}$ Finally, $u_{l o, t}$ is a utility flow, to be specified below, which stems from the degrees of satisfaction of household members with their locations of residence.

\footnotetext{
${ }^{12}$ My constraint does not allow non-movers to increase debt after house prices increase. Allowing for home equity loans would introduce a nonlinearity that creates severe difficulties when solving the model. Note, however, that the key aspect of the proposed geographical mobility channel is that agents can protect their debt limits from declines in house prices by not moving.

${ }^{13}$ The model abstracts from mortgage default. But note that homeowners who default are likely to have difficulties in getting a new mortgage for an even longer period of time.

${ }^{14}$ This construct was introduced by Merz (1995) and was followed by others, including Gertler and Trigari (2009). According to this setup, agents are fully insured against fluctuations in consumption that arise from idiosyncratic shocks. What follows is a framework with a representative saver and a representative borrower.

${ }^{15}$ For reasons of simplicity, geographic locations are not explicitly modeled, although one could think of the model as one with a continuum of locations that are a priori identical to agents. Nonetheless, the model is consistent with two essential aspects of the geographical mobility channel, namely that (i) moving necessitates refinancing a mortgage and (ii) in some cases moving is required to accept a job offer.

${ }^{16}$ In quantitative model simulations, the parameter $\kappa$ will be set to a negative number, which means that unemployment creates disutility to the household. One can think of this disutility as the psychological costs associated with unemployment.
} 
Consumption and borrowing decisions: Each period, households decide on the amount of non-durable consumption, housing and borrowing. In doing so, they are restricted by the following budget constraint:

$$
c_{t}+p_{h, t}\left(h_{t}-h_{t-1}\right)+\zeta n_{m, t}+R_{t-1} d_{t-1}=\left(1-n_{u, t}\right) y_{t}+d_{t},
$$

where $p_{h, t}$ is the house prices in units of non-durables, $\zeta$ is the fixed cost of moving a member, $n_{m, t}$ is the fraction of members that moves, $R_{t}$ is the gross interest rate on debt to be repaid in period $t+1, y_{t}$ is wage income per employed member, and $d_{t}$ is the amount of debt. ${ }^{17}$ Thus, income consists of wage income, new debt and the sales value of the housing stock of the previous period, and income is spent on non-durable consumption, housing, moving costs, and servicing of old debt.

Debt is limited by a collateral constraint. In the literature on business cycle models with collateral constraints, it is standard to assume that a household can borrow up to a fraction $\chi$ of the value of the house. The collateral constraint then reads $d_{t} \leq \chi p_{h, t} h_{t}$, with $1-\chi$ being the downpayment as a fraction of the value of the house. It is also standard to assume that all debt is refinanced in every period, which implies that a fall in house prices directly affects all collateral-constrained borrowing in the economy. In reality, however, only those households who take out a new mortgage loan face a renewal of the downpayment requirement. Many homeowners simply roll over their existing mortgage contracts and for those households, the relevant constraint is $d_{t} \leq d_{t-1}$ (abstracting from amortization). Movers, however, are typically forced to take out a new mortgage loan. Accounting for these realities, I assume that the fraction of debt that the household needs to refinance equals the mobility rate, which delivers the following constraint ${ }^{18}$ :

$$
d_{t} \leq n_{m, t} \chi p_{h, t} h_{t}+\left(1-n_{m, t}\right) d_{t-1} .
$$

The important feature of this constraint is that the fraction of debt that is refinanced depends on the mobility rate, $n_{m, t}$. If all members move, that is when $n_{m, t}=1$, all debt is refinanced and the constraint reduces to a standard collateral constraint. If none of the members moves, that is when $n_{m, t}=0$, the household can borrow up to the amount of the previous period, that is up to $d_{t-1} \cdot{ }^{19}$ For a given housing stock, $h_{t}$, a decline in the house price $p_{h, t}$ lowers $\chi p_{h, t} h_{t}$ relative to $d_{t-1}$. This makes moving less attractive. Note that in a steady state, the borrowing constraint reduces to a standard collateral constraint. Given the presence of patient households with a higher discount factor, this constraint binds in the steady state. ${ }^{20}$

The first-order conditions for the amount of housing and debt are ${ }^{21}$

$$
\begin{aligned}
& \frac{p_{h, t}}{c_{t}}=\frac{\alpha z_{h, t}}{h_{t}}+\beta E_{t} \frac{p_{h, t+1}}{c_{t+1}}+\lambda_{c c, t} n_{m, t} \chi p_{h, t}, \\
& \frac{1}{c_{t}}=\beta E_{t}\left(\frac{R_{t}}{c_{t+1}}-\lambda_{c c, t+1}\left(1-n_{m, t+1}\right)\right)+\lambda_{c c, t} .
\end{aligned}
$$

Eq. (4) is the first-order condition for the amount of housing. The right hand side is the shadow value of housing, which consists of three terms. The first term captures the direct utility gain derived from a marginal unit of housing. The second term is the utility derived from the discounted resale value of the house in the next period. The third term is proportional to the Lagrange multiplier of the borrowing constraint, $\lambda_{c c, t}$, the real house price $p_{h, t}$, and the mobility rate $n_{m, t}$. This term stems from the additional borrowing capacity that an extra unit of housing generates. If the borrowing constraint is not binding or if no member moves, this term reduces to zero. Eq. (4) states that at the optimum, the shadow value of housing must be equal to the utility derived from $p_{h, t}$ marginal units of non-durables. Eq. (5) is the Euler equation for debt. A binding borrowing constraint introduces a wedge in this equation. The second term within the conditional expectation represents the fact that of the new debt taken on in period $t$, only a fraction $n_{m, t+1}$ will be refinanced in period $t+1$. The remaining debt is rolled over to period $t+2$.

Location preferences: Geographical mobility is an essential feature of the model. Naturally, mobility decisions are affected by a number of factors. The focus of this paper is on considerations regarding employment and borrowing. However, mobility decisions also depend on other factors, such as changes in family composition or changes in the degree of satisfaction with the neighborhood. In order for the model to generate realistic mobility rates, these considerations need to be taken into account.

The setup is as follows. For each individual member $j$, an idiosyncratic location satisfaction shock $\varepsilon_{j, t}$ is observed during period $t$. This shock represents the private factors that affect how willing someone is to move. For members who do not move, the realization of $\varepsilon_{j, t}$ is received as a utility flow, while for each mover a fixed utility flow $\psi$ is received. ${ }^{22}$ Hence, for members with a low realization of $\varepsilon_{j, t}$, moving is relatively attractive. For those members who receive a "long-distance job offer", moving has an additional benefit, namely that it enables them to escape unemployment.

\footnotetext{
${ }^{17}$ I limit the attention to loans with variable interest rates, so refinancing only involves the enforcement of a renewed collateral constraint.

${ }^{18}$ I abstract from home equity loans.

19 Campbell and Hercowitz (2009) consider a model in which debt also evolves in a recursive way. In their model, however, the weight of old debt in the constraint depends on a fixed amortization rate. In my model, it depends on the mobility rate, which is a choice variable.

${ }^{20}$ In the simulations, one can verify that shocks are never large enough to bring the Lagrange multiplier on the borrowing constraint even close to zero. See also Iacoviello (2005) for a discussion on this issue.

${ }^{21}$ A full derivation of the households' first-order conditions can be found in online Appendix B.

22 The mobility decision thus depends on the difference between $\varepsilon_{j, t}$ and $\psi$. In quantitative model simulations, I will set $\psi$ to a negative number. This implies that a move creates a flow of disutility to the household, which can be thought of as the effort that moving requires. The mean of the idiosyncratic shock, $\varepsilon_{j, t}$, is normalized to zero.
} 
The optimal mobility decision implies a cutoff level for the location satisfaction shock. If the realization of this idiosyncratic shock is below the cutoff level, the member moves, while the member does not move if the realization is above the cutoff level. Thus, the cutoff level represents the location satisfaction of the marginal mover, being exactly indifferent between moving and not moving. Although there may in principle be different cutoff levels for different agents, depending on individual characteristics such as wealth and labor income, the advantage of the present framework with full income sharing among household members is that there are only two such values: one for members with a long-distance job offer, denoted by $\bar{\varepsilon}_{d o, t}$, and one for those without such an offer, denoted by $\bar{\varepsilon}_{t}$. Let $F(\cdot)$ be the cumulative distribution function of the shock. Thus, $F\left(\bar{\varepsilon}_{d o, t}\right)$ is the mobility rate among members with a long-distance job offer and $F\left(\bar{\varepsilon}_{t}\right)$ is the mobility rate among the members without such a job offer. It follows from this setup that the total location satisfaction utility term in (1) is given by

$$
u_{l o, t}=n_{d o, t}\left[\psi F\left(\bar{\varepsilon}_{d o, t}\right)+\int_{\bar{\varepsilon}_{\mathrm{do}, t}}^{\infty} \varepsilon d F(\varepsilon)\right]+\left(1-n_{d o, t}\right)\left[\psi F\left(\bar{\varepsilon}_{t}\right)+\int_{\bar{\varepsilon}_{t}}^{\infty} \varepsilon d F(\varepsilon)\right],
$$

where $n_{d o, t}$ is the fraction of members with a long-distance job offer.

Mobility decisions: The two cutoff levels that determine the mobility rate are chosen optimally by the household. This decision is taken at the beginning of the period, jointly with consumption and borrowing decisions. ${ }^{23}$ The corresponding first-order conditions are

$$
\begin{aligned}
& \psi=\frac{\zeta}{c_{t}}+\bar{\varepsilon}_{t}-\lambda_{c c, t}\left(\chi p_{h, t} h_{t}-d_{t-1}\right), \\
& \bar{\varepsilon}_{d o, t}-\bar{\varepsilon}_{t}=\frac{y_{t}}{c_{t}}-\kappa+\left(1-\rho_{u}\right) G_{t} .
\end{aligned}
$$

Eq. (6) is the first-order condition for $\bar{\varepsilon}_{t}$, the moving cutoff for members without a long-distance job offer. The left- and the right-hand side of this equation are, respectively, the benefits and costs of moving, for a member who is exactly indifferent between moving and staying. On the left-hand side, $\psi$ is the utility flow that is received for being at a new location. On the right-hand side, the first term is the utility loss arising from paying the moving cost $\zeta$. The second term, $\bar{\varepsilon}_{t}$, is the utility flow received when staying at the current location, which is foregone when moving. The third term arises from the effect of mobility on the borrowing capacity of the household and can be either positive or negative. If the borrowing limit on old loans exceeds the borrowing limit on new loans (that is, when $\chi p_{h, t} h_{t}<d_{t-1}$ ), there is an additional cost to mobility.

Eq. (7) determines the cutoff level for members with a long-distance job offer, $\bar{\varepsilon}_{d o, t}$, relative to the cutoff for members without such a job offer. The difference between $\bar{\varepsilon}_{d o, t}$ and $\bar{\varepsilon}_{t}$ is determined by two factors. The first factor is the difference in utility gains from the wage income of an employed member, $y_{t} / c_{t}$, and the utility flow from unemployment, $\kappa$. The second factor stems from a dynamic composition effect. If more members with a long-distance job offer move, more members flow into employment, which positively affects the fraction of members that is employed in future periods. This effect is captured by $G_{t}$, which is defined in online Appendix B.

The key mechanism through which fluctuations in house prices affect real activity can be understood from the two equations above. Ceteris paribus, a decline in the house price, $p_{h, t}$, must be offset by a decline in the cutoff, $\bar{\varepsilon}_{t}$. Members move when their individual location satisfaction is below the cutoff. Thus, with a lower cutoff, mobility declines. Other things equal, a decline in $\bar{\varepsilon}_{t}$ also lowers the cutoff for members with a long-distance job offer, $\bar{\varepsilon}_{d o, t}$. When mobility of members with longdistance job offers declines, a larger fraction of job offers is turned down, pushing up aggregate unemployment.

Flow equations: The mobility rate among household members, $n_{m, t}$, follows from the mobility cutoffs, and is given by $n_{m, t}=n_{d o, t} F\left(\bar{\varepsilon}_{d o, t}\right)+\left(1-n_{d o, t}\right) F\left(\bar{\varepsilon}_{t}\right)$. Let aggregate variables be denoted by a hat. The fraction of members with a long-distance job offer, $n_{d o, t}$, is determined by $n_{d o, t}=\omega \widehat{g}_{t-1} n_{s, t}$. Here, $\widehat{g}_{t}$ is the probability that an unemployed member meets a firm and gets a job offer, $\omega$ is the fraction of all meetings in which a member is required to move to accept the offer, and $n_{s, t}$ is the fraction of members that is searching for a job, which satisfies $n_{s, t}=n_{u, t}+\rho_{u}\left(1-n_{u, t}\right)$, where $\rho_{u}$ is the job destruction rate. Thus, the group of job searchers consists of the members that are unemployed and the employed members who just became obsolete at their current job. The fraction of unemployed members is equal to the fraction of job searchers of the previous period that did not receive a job offer, or that did receive a job offer but rejected it because moving is too unattractive: $n_{u, t}=n_{s, t-1}\left(1-\widehat{g}_{t-1}+\omega \widehat{g}_{t-1}\left(1-F\left(\bar{\varepsilon}_{d o, t}\right)\right)\right)$.

\subsubsection{Patient households}

Patient households are the same as impatient households, except that their discount factor, $\gamma$, is higher than the discount factor of the impatient households, $\beta$. In equilibrium, patient households therefore lend to the impatient households and as a consequence the patient households are not borrowing constrained. Also, patient households own the firms and receive their profits. For patient households, house prices are not directly relevant for mobility decisions because they do not borrow. Let the variables of the patient households be denoted by a tilde. The optimal moving cutoff for members of the patient household without a distant job offer is given by $\tilde{\bar{\varepsilon}}_{t}=\psi-\frac{\zeta}{\tilde{c}_{t}}$.

${ }^{23}$ When mobility decisions are taken, it is known what members have what type of job offers, because offers were received at the end of the previous period. 


\subsubsection{Labor market}

Let $\nu$ be the share of impatient households in the total population. The aggregate unemployment rate and the aggregate number of job searchers are, respectively, $\widehat{n}_{u, t} \equiv \nu n_{u, t}+(1-\nu) \tilde{n}_{u, t}$ and $\widehat{n}_{s, t} \equiv \nu n_{s, t}+(1-\nu) \tilde{n}_{s, t}$.

The labor market is characterized by a matching friction. The aggregate number of meetings between firms and job candidates, $\widehat{m}_{t}$, is a Cobb-Douglas function of the total number of job searchers, $\widehat{n}_{u, t}$, and of $\widehat{v}_{t}$, the aggregate number of vacancies: $\widehat{m}_{t}=\mu \widehat{n}_{s, t}^{\eta} \widehat{v}_{t}^{1-\eta}$, where $\eta$ is again the elasticity parameter, and $\mu$ is a scaling parameter. The probability that a job searcher meets with a firm is $\widehat{g}_{t} \equiv{\frac{m_{t}}{\widehat{n}_{s, t}}}_{\text {and }}$ the probability that a firm fills a vacancy is $\widehat{g}_{f, t} \equiv \widehat{\frac{m}{t}}_{v_{t}}$.

\subsubsection{Firms, exogenous processes and market clearing}

Firms that are matched to a worker produce $z_{a, t}$ per period, where $z_{a, t}$ follows an exogenous process with a steady-state level equal to one. The wage is simply a share $\xi$ of total revenues, that is $y_{t}=\xi z_{a, t}$. The firm receives the remaining share $1-\xi .^{24}$ Since firms are owned by the patient households, they discount future profits using the stochastic discount factor of those households. The asset value of a match to a firm, $V_{t}$, satisfies

$$
V_{t}=(1-\xi) z_{a, t}+\left(1-\rho_{u}\right) E_{t} \tilde{\Lambda}_{t, t+1} V_{t+1}
$$

where $\tilde{\Lambda}_{t, t+1}$ is the stochastic factor of the patient households, that is, $\tilde{\Lambda}_{t, t+1} \equiv \gamma_{\tilde{c}_{t+1}}$. Firms that search for employees pay a vacancy cost $\vartheta$ per period. Free entry of firms in the goods market implies that the vacancy cost equals the expected benefit to the firm of posting a vacancy

$$
\vartheta=\widehat{g}_{f, t} E_{t}\left(1-\omega+\omega \frac{\nu n_{s, t}}{\widehat{n}_{s, t}} F\left(\bar{\varepsilon}_{d o, t+1}\right)+\omega \frac{(1-\nu) \tilde{n}_{s, t}}{\widehat{n}_{s, t}} F\left(\tilde{\bar{\varepsilon}}_{d o, t+1}\right)\right) \tilde{\Lambda}_{t, t+1} V_{t+1} .
$$

The term between large brackets is the fraction of meetings that is unsuccessful because the worker is unwilling to move. Aggregate firm profits are given by $\widehat{\Pi}_{t}=\left(1-\widehat{n}_{u, t}\right)(1-\xi) z_{a, t}-\vartheta \widehat{v}_{t}$.

The housing preference shock, $z_{h, t}$, and the productivity shock, $z_{a, t}$, are assumed to follow AR(1) processes in logs. The supply of the total stock of housing is fixed and normalized to one, that is, $\nu h_{t}+(1-\nu) \tilde{h}_{t}=1$. The aggregate supply of debt is zero, i.e. $\nu d_{t}+(1-\nu) \tilde{d}_{t}=0$. A formal definition of the equilibrium is provided in online Appendix B.

\subsection{Calibration}

The model is calibrated to U.S. data. The frequency is monthly. Several parameters are calibrated to pin down essential steady-state properties of the model and one parameter is calibrated to match the volatility of home sales.

The calibration procedure targets six steady-state outcomes. First, the aggregate unemployment rate in the steady state is five percent. Second, the steady-state aggregate mobility rate is 0.65 percent per month. This corresponds to an annual mobility rate of 7.5 percent, as measured for U.S. homeowners using data from the Current Population Survey (CPS) for the period 2000-2005. Third, the steady-state mobility rate due to members with long-distance job offers is 0.10 percent per month. This choice is based on data from the CPS for the period 2000-2005 as well. On average, about 15 percent of the owners who had moved indicated that the move was primarily for employment reasons. Fourth, the steady-state value of housing wealth is 140 percent of annual output, following Iacoviello, 2005. Fifth, the credit-constrained households consume the same amount of housing in the steady state as the patient households. ${ }^{25,26}$ Sixth, the probability that a vacancy is filled is 0.34 in the steady state. This implies a quarterly probability of 0.71 , as in den Haan et al. (2000)).

The parameter values are presented in Table 2. The calibration of the discount factors follows Iacoviello and Neri (2010). The discount factor of the patient households, $\gamma$, is set to 0.9975 , which implies a steady-state real interest rate of about three percent per annum. The discount factor of the impatient households, $\beta$, is set to 0.9899 . The weight of housing in the utility function, $\alpha$, is set differently for patient and impatient households. The values follow from the steady-state targeting procedure described above. The value for the patient and impatient households are 0.043 and 0.139 , respectively. The relatively high value for the impatient households is a direct consequence of the requirement that both types of households consume the same amount of housing in the steady state. ${ }^{27}$

The roles of the moving cost parameter, $\zeta$, and the utility flow from moving, $\psi$, are similar. This can be seen from Eq. (6), the first-order condition for the mobility cutoff $\bar{\varepsilon}_{t}$. The parameter $\zeta$ captures physical costs of moving, such as transaction

\footnotetext{
${ }^{24}$ I deviate from the more standard assumption that firms and workers bargain over the surplus that is created by an employment relationship. Instead, I assume that firms post wage contracts in which the worker gets a fixed fraction of the revenues. This setup makes the model tractable but also seems reasonable, given that in this model the total surplus of the match is affected by the utility derived from mobility. It does not seem very plausible that firms would be able to observe the entire surplus and engage in bargaining over it.

${ }^{25}$ This choice is supported by data from the American Household Survey 2007. For households with the very lowest down payment ratios (up to five percent), the median home value is below the median home value for the total sample of homeowners. However, the median home value for households with a down payment ratio between six and 20 percent is higher than the median for the total sample.

${ }^{26}$ Note that when the steady-state value of the housing stock owned by patient households is pinned down, the borrowing constraint determines the steady-state level of mortgage debt. The steady-state level of aggregate debt relative to aggregate income is 22.4 percent.

${ }^{27}$ Note that impatient households discount the future resale benefits from housing more heavily than patient households. This would lead them to consume much less housing in the steady state than the patient households. As a consequence, the steady state level of debt of the impatient households would be unrealistically low.
} 
Table 2

Parameter values for the baseline model.

\begin{tabular}{|c|c|c|c|}
\hline Parameter & Description & value & Source/target \\
\hline$\beta$ & Discount factor impatient h.h. & 0.9899 & Iacoviello and Neri (2010) \\
\hline$\gamma$ & Discount factor patient h.h. & 0.9975 & Iacoviello and Neri (2010) \\
\hline$\alpha^{i m p}$ & Housing pref. impatient h.h. & 0.140 & Steady state \\
\hline$\alpha^{p a t}$ & Housing pref. patient h.h. & 0.043 & Steady state \\
\hline$\psi$ & Utility from new location & -7.068 & steady state \\
\hline$\sigma$ & St. dev. location preference shock & 3.47 & volatility mobility \\
\hline$\zeta$ & Moving cost & 1.6 & Stokey (2009) \\
\hline$\rho_{u}$ & Rate of job destruction & 0.035 & Gertler and Trigari (2009) \\
\hline$\eta$ & Elasticity matching function & 0.6 & Petrongolo and Pissarides (2001) \\
\hline$\mu$ & Level parameter matching function & 0.545 & steady state \\
\hline$\vartheta$ & Vacancy cost & 0.181 & steady state \\
\hline$\omega$ & Fraction of long-distance job offers & $1 / 3$ & no source, check for robustness \\
\hline$\xi$ & Wage rule parameter & 0.98 & 2 percent accounting profits \\
\hline$\kappa$ & Utility from unemployment & -4.381 & steady state \\
\hline$\nu$ & Share impatient h.h. & 0.2 & AHS / SCF data \\
\hline$\chi$ & Collateral requirement & 0.8 & Campbell and Hercowitz (2009) \\
\hline$\phi_{h}$ & Autocorr. housing pref. process & 0.983 & Same as tech. process \\
\hline$\phi_{a}$ & Autocorr. technology process & 0.983 & Kydland and Prescott (1982) \\
\hline
\end{tabular}

costs and fees for real estate agents. Following Stokey (2009), $\zeta$ is set to eight percent of the steady-state value of a unit of housing. The parameter $\psi$ is used in the steady-state targeting procedure and its value is -7.068 .

The elasticity of the number of matches with respect to the number of job searchers, $\eta$, is set to 0.6 . The job destruction probability, $\rho_{u}$, is set to 0.035 . These values are within the range of standard values considered in the literature and follow Gertler and Trigari (2009). The values of the scaling parameter in the matching function, $\mu$, and the vacancy cost, $\vartheta$, follow from the steady-state targeting procedure, and are 0.545 and 0.181 , respectively. The calibration implies that in the steady state 1.86 percent of output is devoted to vacancy costs.

The fraction of long-distance job offers, $\omega$, is difficult to calibrate as there is no direct equivalent in the data. My strategy is to set $\omega$ to one-third and check for robustness. Alternative values for $\omega$ turn out to generate very similar results. ${ }^{28}$ The parameter $\xi$ controls the fraction of the revenues that flows to workers in the form of wages. I assume that accounting profits of the firms are two percent, that is, $\xi=0.98$. This choice is in line with typical calibrations of matching models, see Hornstein et al. (2005). The parameter $\kappa$ measures the utility flow received per unemployed worker, and is one of the parameters that are used to match the steady-state targets. Since its value is negative $(\kappa=-4.381)$, unemployment creates a disutility flow to the household, which one can interpret as a psychological cost of unemployment. ${ }^{29}$

The collateral requirement parameter, $\chi$, is set to 0.8. Campbell and Hercowitz (2009) document that during the period 1983-2001, the average equity stake in newly purchased homes declined from 22.6 percent to 16.4 percent. ${ }^{30}$ In the model, $1-\chi$ is the equity stake in the steady state. The fraction of borrowing-constrained households, $\nu$, is calibrated to capture the real-world fraction of borrowing-constrained households in the total population (including renters). Data from the Survey of Consumer Finances (SCF) show that during the period 1989-2007, the fraction of households with a mortgage or home equity loan increased from 39 percent to 46 percent. Of course, not all these households are actually constrained by a borrowing limit. In the baseline calibration, $\nu$ is set equal to $0.2 .^{31}$

The calibration of the persistence parameter of the productivity process follows Kydland and Prescott (1982). The persistence parameter of the housing preference process is set to the same value, since there are few reasons to believe that housing preferences should be either more or less persistent than productivity. Finally, the idiosyncratic location satisfaction shock is calibrated to be normally distributed with mean zero and standard deviation $\sigma$. The parameter $\sigma$ is important for the volatility of geographical mobility and its calibration targets the volatility of home sales relative to house prices over the period 1970-2010, which is 2.4. For this purpose, I guess a value of $\sigma$ and construct a simulation such that the model precisely replicates observed time series for the real house price and GDP for the period 1970-2010, initializing the model at

\footnotetext{
${ }^{28}$ The reason is that the steady-state fraction of the workers accepting long-distance job offers is a direct target of the calibration procedure.

29 The negative value for $\kappa$ contrasts with standard models with Nash bargaining, in which the parameter is typically positive-valued. In those models, however, the main role of $\kappa$ is to determine the surplus from a match, affecting the incentives for firms to post vacancies. In my model, $\kappa$ is only relevant in that it affects the incentives for unemployed workers to accept long-distance job offers. To appreciate this point, note that $\kappa$ only enters the first-order condition for the mobility cutoff for workers with a long-distance offer. Therefore, a low value of $\kappa$ ensures that in the steady state a realistic fraction of workers moves for employment reasons. An important reason why the value of $\kappa$ has to be so low is that in the model there are complete insurance markets, and therefore unemployed agents do not suffer from lower levels of consumption than employed agents.

30 The average is over home purchases with an equity stake of at most 50 percent.

31 Data from the American Housing Survey (AHS) show that in 2007, 62 percent of all mortgagors had put in a downpayment of 15 percent or less at the time they purchased their home. Earlier observations are not available.
} 
the steady state prior to $1970 .^{32}$ I then compute the relative volatility of mobility, update the guess for $\sigma$, and repeat the procedure until the relative volatility of mobility equals 2.4. The value for $\sigma$ resulting from this procedure is 3.47.

\section{Model results}

The model is solved using a first-order perturbation method and then simulated. ${ }^{33}$ Three types of experiments are conducted. First, I discuss the dynamic responses to one-time shocks in productivity and housing preferences. Second, I use the model to compute business cycle statistics, which are compared to those found in the data. Next, I zoom in on the Great Recession period. Finally, I consider a model with sticky wages.

\subsection{Dynamic responses}

Productivity shock: Responses to a sudden one-percent decline in productivity are shown in Fig. 3. First, consider the baseline model. After a decline in productivity, output and house prices fall. As in standard business cycle models with search and matching frictions, there is a decline in vacancies and in the (average) unemployment outflow hazard, and an increase in the unemployment rate. The mobility rate falls after the decline in productivity.

To understand the effects of refinancing constraints, consider the responses for an economy in which there are no impatient households (labeled "no borrowers"). In such an economy, all households have the same discount factor and there is no debt in equilibrium. Thus, refinancing constraints are irrelevant. The responses for this economy are plotted in Fig. 3 as well. Without credit-constrained households, the decline in vacancies is very similar to the decline predicted by the baseline model. The unemployment rate, however, does not increase as much as in the baseline model. Thus, the presence of credit-constrained households implies a somewhat flatter Beveridge curve. This is directly related to the fact that the drop in the mobility rate is also much less pronounced than in the baseline economy. The declines in output and house prices, however, are quite similar across the two versions of the model, as they are mainly driven by the direct effects of the fall in productivity.

Housing preference shock: How do shocks that originate in housing markets affect the real economy? Fig. 4 displays the responses to a negative housing preference shock, generating a house price decline of about 10 percent on impact. First consider the baseline model. The model predicts a joint decline in house prices, mobility, output, vacancies and the unemployment outflow hazard, and an increase in the unemployment rate.

The increase in the unemployment rate is more persistent than the decline in vacancies. Fifteen quarters after the shock, the number of vacancies has nearly returned to its steady-state level, but the unemployment rate is still well above its steady-state level. Persistence is also observed in the decline of the mobility rate, which is much more prolonged than the fall in house prices. Six years after the shock, house prices have almost fully recovered, but the mobility rate is still 10 percent below its steady-state level.

Why do vacancy postings decline following a negative housing shock? This decline is related to the fact following a tightening of the borrowing constraint, impatient households sell houses to the patient households. In order to finance these purchases, the patient households cut back on non-durable consumption, implying a decrease in their stochastic discount factor, $\tilde{\Lambda}_{t, t+1}$. Since the firms are owned by the patient households, a decrease in $\tilde{\Lambda}_{t, t+1}$ implies that the benefits from posting a vacancy are more heavily discounted. Therefore, vacancy posting decreases. This effect becomes clear when observing the free-entry condition, Eq. (9). The intuition is that in order to take advantage of the increase in returns on housing, patient households reduce their investments in vacancies. Also, the benefits from vacancy posting decrease when more job offers are turned down.

What are the effects of collateral constraints? Fig. 4 shows that in the economy without credit-constrained households, the decline in house prices is smaller than in the baseline economy. But more importantly, real activity variables do not respond at all to the shock. To see why, note that the first-order condition for housing of the patient households is given by

$$
\frac{p_{h, t}}{\tilde{c}_{t}}=\frac{\alpha z_{h, t}}{\tilde{h}_{t}}+\gamma E_{t} \frac{p_{h, t+1}}{\tilde{c}_{t+1}} .
$$

Without credit-constrained households, this is the only model equation in which $p_{h, t}$ enters, which implies that house prices and housing preferences are irrelevant for real allocations. ${ }^{34}$

\footnotetext{
32 This is done recursively: given the values of the endogenous state variables, one can back out the realized productivity and housing preference shocks by inverting the model's recursive solution for output and the real house price. These shocks can then be used to compute next period's endogenous state variables, etc. This procedure is equivalent to using the Kalman filter, given that the model parameters are known and that the initial state of the economy is known with certainty. Data were logged and linearly detrended. Quarterly GDP data were converted into monthly data by linear interpolation. The results are not very sensitive with respect to the assumption that the economy starts off at the steady state in 1970 .

${ }^{33}$ Thus, the quantitative experiments abstract from nonlinearities that may arise after large shocks. Also, the model abstracts from effects arising from the zero lower bound on nominal interest rates.

${ }^{34}$ One could simply remove Eq. (10) from the system of equilibrium conditions, since one would lose one equation and one endogenous variable. Since the aggregate supply of housing is fixed, the house price drops out of the budget constraint.
} 

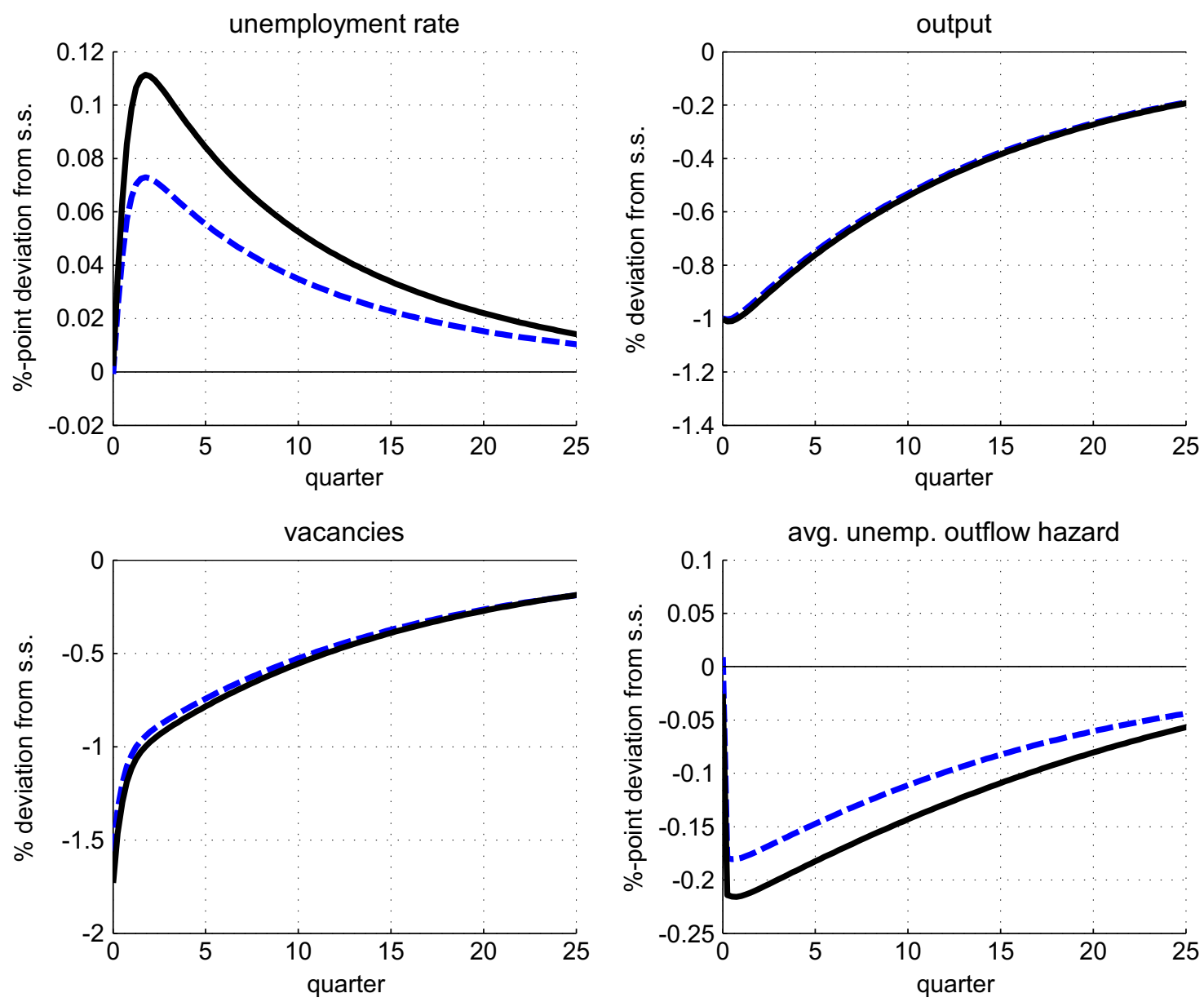

number of movers

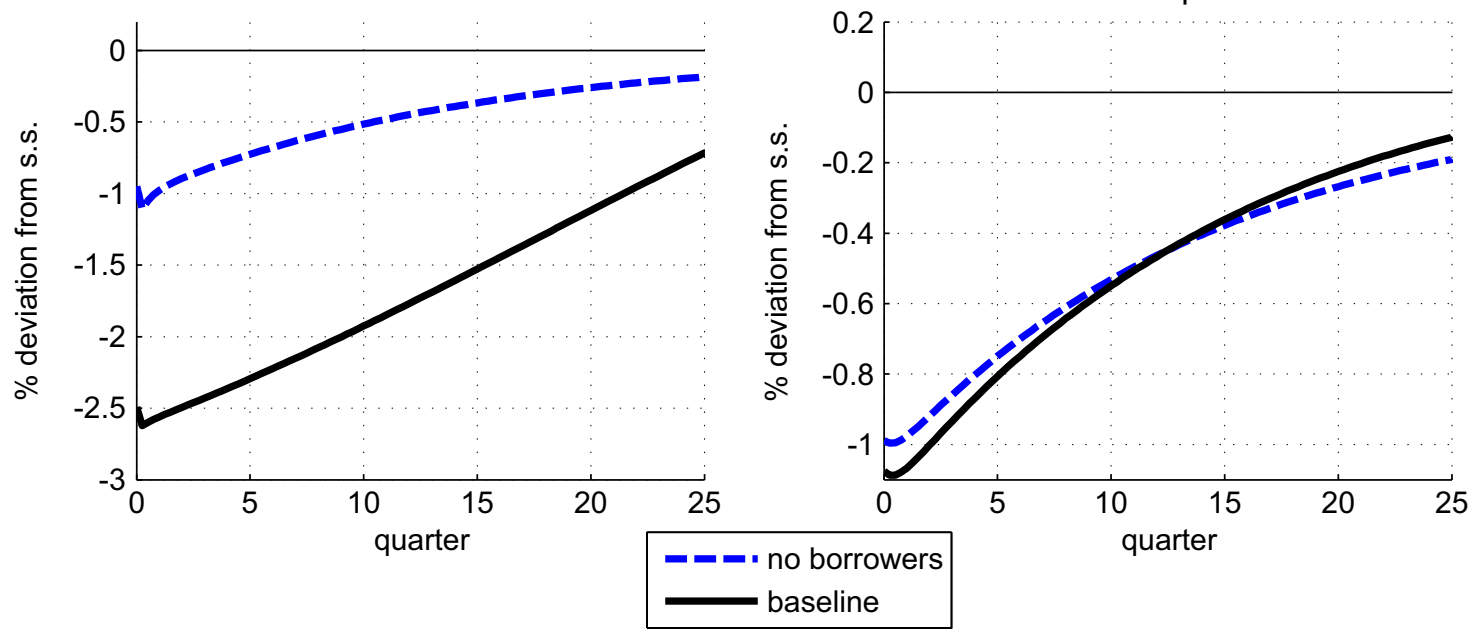

Fig. 3. Responses to a negative productivity shock. Notes: The shock is scaled such that productivity declines by 1 percent on impact. "No borrowers" refers to a version of the model in which the fraction of impatient households is set to zero. 

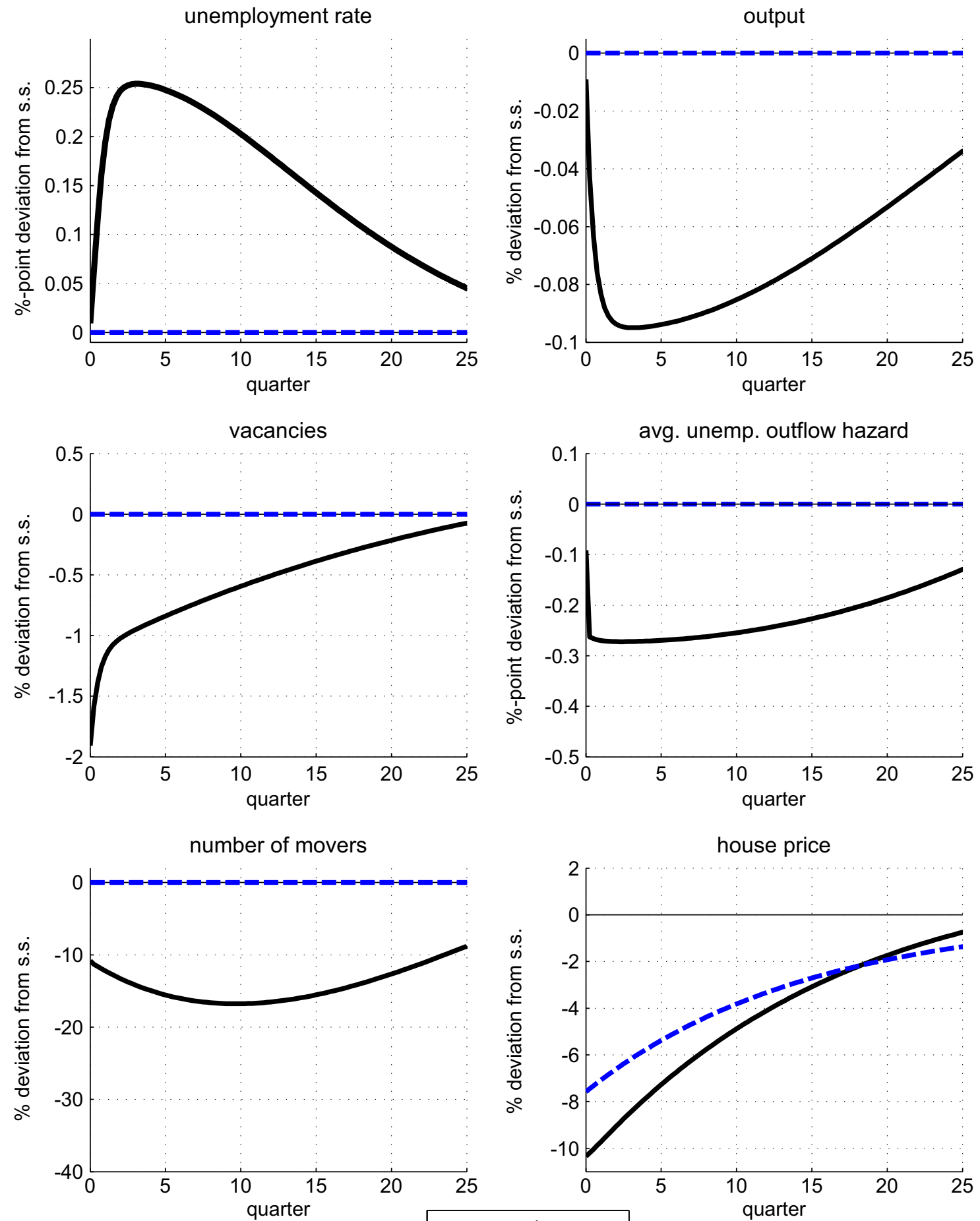

$$
\begin{array}{|c|}
\hline \boldsymbol{E} \text { ' no borrowers } \\
\text { baseline }
\end{array}
$$

Fig. 4. Responses to a negative housing preference shock. Notes: The shock is scaled such that the house price declines by 10 percent on impact in the baseline model. "No borrowers" refers to a version of the model in which the fraction of impatient households is set to zero.

\subsection{Business cycle statistics}

This section investigates how well the model can account for key cyclical patterns present in the data. The analysis is based on the model simulation for the period 1970-2010, described at the end of Section 3.2. Model-predicted business cycle 

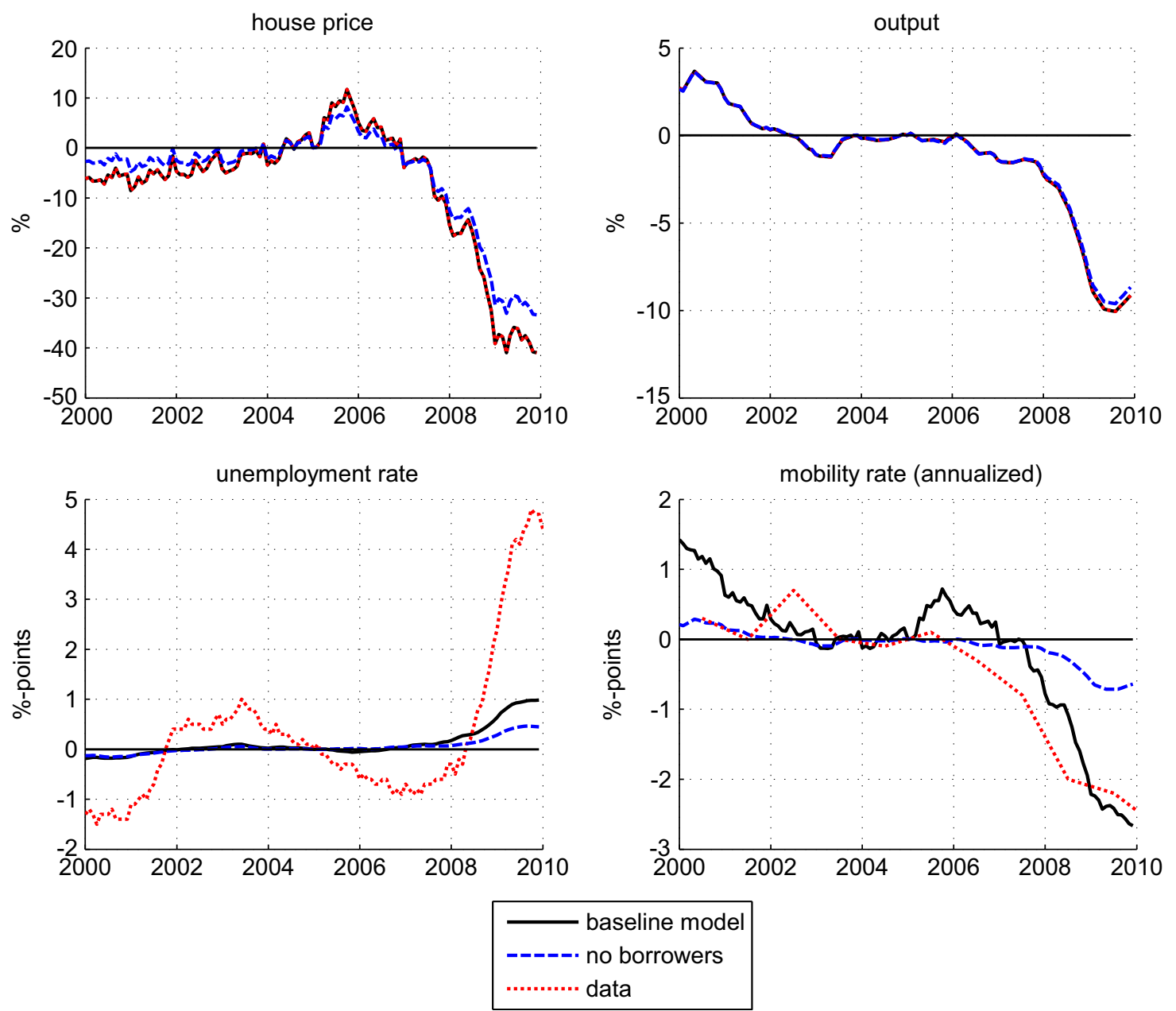

Fig. 5. Great recession experiment: model predictions versus data. Notes: All panels plot deviations from the level in January 2005 . The shocks fed to the models are such that the baseline model matches exactly observed data series for the real house price and output (linearly de-trended) over the period 1970-2010, starting from the steady state in 1970. "No borrowers" refers to a version of the model with the same shocks as in the baseline, but in which the fraction of impatient households is set to zero. Data source mobility rate: Current Population Survey. (For interpretation of the references to color in this figure caption, the reader is referred to the web version of this paper.)

statistics are displayed in the middle panel of Table 1 . By construction, the model closely matches the volatility of house prices relative to GDP in the data. ${ }^{35}$ The same holds for the volatility of mobility, which is an explicit calibration target. An important success of the model, however, is that it predicts a positive correlation between house prices and mobility (0.51) which is very close to its empirical counterpart (0.55). The model also accounts reasonably well for the negative correlation between house prices and unemployment and between mobility and unemployment. Further, the model reproduces the empirical Beveridge Curve, i.e. the strong negative correlation between unemployment and vacancies. The predicted volatilities of unemployment and vacancies, however, are very low compared to data. This is a general problem of labor market matching models, as emphasized by Shimer (2005).

The bottom panel of Table 1 presents statistics computed from a counterfactual simulation in which all housing preference shocks are set to zero. Without these shocks, the model cannot account for the observed volatilities of house prices and homeowner mobility. Further, this version of the model predicts a counterfactually strong correlation between unemployment and house prices. Furthermore, without housing shocks, the correlation between house prices and mobility is too strong in comparison to the data.

\footnotetext{
${ }^{35}$ The empirical and model-predicted volatility do not exactly coincide since the model simulation is monthly and the statistics in the upper panel are based on quarterly data.
} 

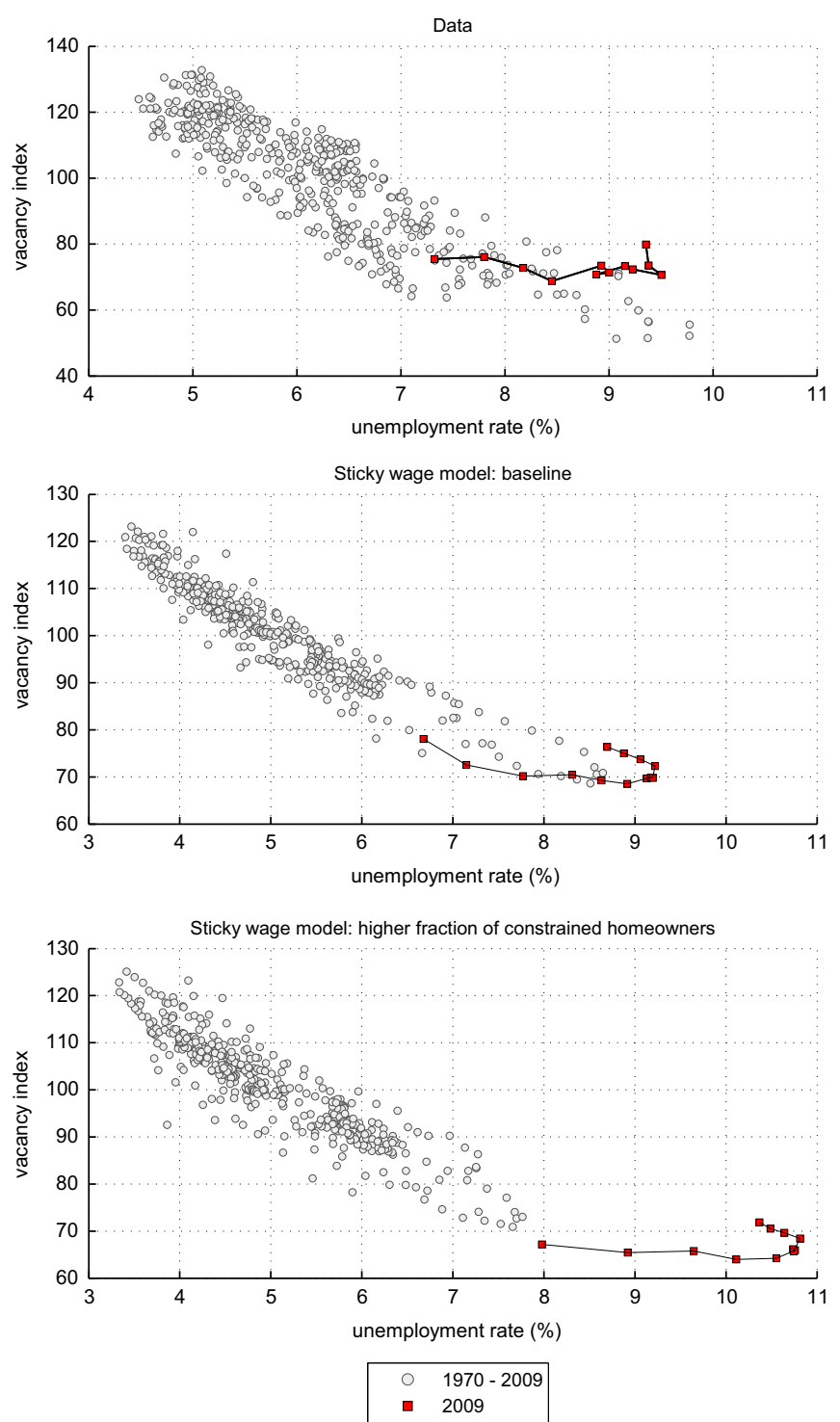

Fig. 6. Beveridge curve in the data, in the baseline sticky-wage model and in the sticky-wage model with a higher fraction of credit-constrained homeowners. Notes: see Fig. 1.

\subsection{Great recession experiment}

This subsection zooms in on the model's predictions for the Great Recession. Fig. 5 illustrates the model's predictions for the real house price, the level of aggregate output, the unemployment rate and the mobility rate over the period 2000-2010, together with real-world data. By construction, the model reproduces the data on house prices and output exactly. The data series on the mobility rate is the mobility rate among homeowners as reported in the Current Population Survey (CPS). ${ }^{36}$

The baseline model predicts a sharp increase in unemployment during 2008, although the magnitude of the increase is smaller than in the data. The model also predicts a sharp decline in the mobility rate, similar to the decline observed in the data. The middle panel of Fig. 1 plots the model-predicted Beveridge curve over the period 1970-2010. The data have been HP-filtered for comparison with the real-world data plotted in the upper panel. For 2009, the model predicts that the Beveridge curve becomes essentially flat, or even somewhat upward sloping, as observed in reality.

Next, I feed the two sets of shocks through a counterfactual model without borrowers $(\nu=0)$. The predictions of this model are plotted using dashed blue lines in Fig. 5. Without borrowers, the model predicts only a very moderate decline in mobility and the increase in the unemployment rate is about 0.6 percentage points lower than in the baseline model. House

${ }^{36}$ This series is only available on an annual basis. The CPS distinguishes between renters and owners. In case the household has moved, the CPS reports the housing tenure status after the move. 
prices and output decline by less than in the baseline, although the differences are modest in a quantitative sense. The bottom panel of Fig. 1 displays the Beveridge curve for the model without borrowers. Compared to the baseline model, the declines in employment and mobility are markedly smaller and the Beveridge curve displays a much smaller outward shift during 2009.

\subsection{Sticky wages}

Not surprisingly, the baseline model is unable to generate realistically large volatilities of unemployment and vacancies. In this subsection, I apply the fix proposed by Hall (2005) by considering an alternative version of the model with a constant wage. In particular, I set the wage equal to its steady-state value in the baseline model and re-compute the shocks over the entire sample period. ${ }^{37}$

The middle panel of Fig. 6 plots the Beveridge Curve predicted by the sticky-wage version of the model, whereas the upper panel again plots real-world data. A comparison between the two panels reveals that the sticky-wage model generates about as much volatility in unemployment and vacancies as present in the data. Again, the model predicts a flattening of the Beveridge curve in 2009.

To explore the quantitative potential of the model, I finally consider a version with both sticky wages and a higher share of credit-constrained owners. In particular, I feed the shocks computed using the baseline sticky-wage model through a version in which the fraction of constrained households, $\nu$, is re-set from 0.2 to 0.67 . The latter number is roughly the homeownership rate in the United States. The Beveridge curve predicted by this version is plotted in the lower panel of Fig. 6. The predicted increase in the unemployment rate during the Great Recession is about 1.5 percentage points higher than in the baseline sticky-wage model.

\section{Concluding remarks}

Both the empirical and the theoretical evidence presented in this paper support the idea that changes in house prices can spill over to the real economy via geographical mobility, although the effects are quantitatively modest in a realistically calibrated version of the model. In future work, it would be interesting to model renters explicitly. Another interesting extension would be to introduce search frictions in the housing market. In the model, the housing stock is essentially traded on a spot market. Ngai and Tenreyro (2015) show that a model with search frictions in the housing market can generate joint (seasonal) movements in house prices and transaction volumes. Finally, a simplification of the model is that it avoids wealth heterogeneity. This has the benefit of simplicity, but since housing wealth and financial wealth are important drivers of fluctuations in mobility in the model, dynamics are potentially even richer in a model with wealth heterogeneity.

\section{Acknowledgments}

I thank Jeff Campbell, Wouter den Haan, Jonas Fisher, Matteo Iacoviello, Marco del Negro, Morten Ravn, Peter Rupert, Ayşegül Şahin, Petr Sedláček, Joseph Tracy, an anonymous referee and various seminar participants for helpful comments. Part of this research was conducted at De Nederlandsche Bank and at the Federal Reserve Bank of New York. I thank the Conference Board for state-level vacancy data. The views expressed in this paper are my own and do not necessarily reflect official positions of any policy institution. All errors are my own.

\section{Appendix A. Supplementary data}

Supplementary data associated with this paper can be found in the online version at http://dx.doi.org/10.1016/j.jmoneco. 2015.04.005.

\section{References}

Andres, J., Bosca, R., Ferri, J., 2011. Household debt and labor market fluctuations. J. Econ. Dyn. Control.

Barnichon, R., Figura, A., 2011. Labor Market Heterogeneities and the Aggregate Matching Function, Working Paper.

Barnichon, R., 2010. Building a composite help-wanted index. Econ. Lett. 109, 175-178.

Campbell, J.R., Hercowitz, Z., 2009. Welfare implications of the transition to high household debt. J. Monet. Econ. 56 (1), 1-16.

Chan, S., 2001. Spatial lock-in: do falling house prices constrain residential mobility? J. Urban Econ. 49 (3), $567-586$.

den Haan, W.J., Ramey, G., Watson, J., 2000. Job destruction and propagation of shocks. Am. Econ. Rev. 90, $482-498$.

Elsby, M., Hobijn, B., Sahin, A., 2010. Labor market in the great recession. Brookings Pap. Econ. Act. 41, 1-69.

\footnotetext{
${ }^{37}$ In the simulation, the probability of finding a job and of filling a vacancy is always between zero and one, and neither firms or employees have incentives to break up a match.
} 
Engelhardt, G., 2003. Nominal loss aversion, housing equity constraints, and household mobility: evidence from the united states. J. Urban Econ. 53 (1), $171-195$.

Farber, H., 2012. Unemployment in the great recession: did the housing market crisis prevent the unemployed from moving to take jobs? Am. Econ. Rev.: Pap. Proc. 102 (3), 520-25.

Favilukis, J., Ludvigson, S., Van Nieuwerburgh, S., 2012. The Macro-economic Effects of Housing Wealth, Housing Finance, and Limited Risk Sharing in General Equilibrium. Working Paper.

Ferreira, F., Gyourko, J., Tracy, J., 2010. Housing busts and household mobility. J. Urban Econ. 68, 34-45.

Gertler, M., Trigari, A., 2009. Unemployment fluctuations with staggered Nash wage bargaining. J. Polit. Econ. 117 (1), $38-86$.

Goetz, C., 2013. Falling House Prices and Labor Mobility: Evidence from Matched Employer-Employee Data. U.S. Census Bureau Working paper, CES 13-43.

Hall, R., 2005. Employment fluctuations with equilibrium wage stickiness. Am. Econ. Rev., 95.

Head, A., Lloyd-Ellis, H., 2012. Housing liquidity, mobility, and the labour market. Rev. Econ. Stud. 79 (4), $1559-1589$.

Henley, A., 1998. Residential mobility, housing equity and the labour market. Econ. J. 108, 447.

Hornstein, A., Krusell, P., Violante, G.L., 2005. Unemployment and vacancy fluctuations in the matching model: inspecting the mechanism. Feder. Reserve Bank Richmond Econ. Q. 91, 19-51.

Iacoviello, M., Neri, S., 2010. Housing market spillovers: evidence from an estimated DSGE model. Am. Econ. J.: Macroecon. 2, 125-164.

Iacoviello, M., Pavan, M., 2013. Housing and debt over the life cycle and over the business cycle. J. Monet. Econ. 60 (2), $221-238$.

Iacoviello, M., 2005. House prices, borrowing constraints, and monetary policy in the business cycle. Am. Econ. Rev. 95 (3), $739-764$.

Karahan, F., Rhee, S., 2013. Geographical Reallocation and Unemployment During the Great Recession: The Role of the Housing Bust. Working Paper.

Kiyotaki, N., Moore, J., 1997. Credit cycles. J. Polit. Econ. 105, 211-248.

Kydland, F., Prescott, E.C., 1982. Time to build and aggregate fluctuations. Econometrica 50, 1345-1370.

Merz, M., 1995. Search in the labor market and the real business cycle. J. Monet. Econ. 34, 269-300.

Molloy, R., Smith, C., Wozniak, A., 2011. Internal migration in the united states. J. Econ. Perspect., 25.

Nenov, P., 2013. Regional Reallocation and Housing Markets in a Model of Frictional Migration. Working Paper

Ngai, R., Tenreyro, S., 2015. Hot and cold seasons in the housing market. Am. Econ. Rev. 104 (12), $3991-4026$.

Petrongolo, B., Pissarides, C., 2001. Looking into the black box: a survey of the matching function. J. Econ. Lit. 39, 390-431.

Pissarides, C.A., 2000. Equilibrium Unemployment Theory, second ed. MIT Press, Cambridge, MA.

Ravn, M.O., Uhlig, H., 2002. On adjusting the Hodrick-Prescott filter for the frequency of observations. Rev. Econ. Stat. 84, 371-375.

Rupert, P., Wasmer, E., 2012. Housing and the labor market: time to move and aggregate unemployment. J. Monet. Econ. 59 (1), $24-36$.

Schulhofer-Wohl, S., 2012. Negative equity does not reduce homeowners mobility. Feder. Reserve Bank Minneapolis Q. Rev., 3511.

Sedláček, P., 2014. Match efficiency and firms' hiring standards. J. Monet. Econ. 61 (2), 123-133.

Shimer, R., 2005. The cyclical behavior of equilibrium unemployment and vacancies. Am. Econ. Rev. 95, 25-49.

Shimer, R., 2007. Reassessing the Ins and Outs of Unemployment. NBER Working Paper 13421.

Stein, J., 1995. Prices and trading volume in the housing market: a model with down-payment effects. Q. J. Econ. 110, 379-406.

Stokey, N., 2009. Moving costs, nondurable consumption, and portfolio choice. J. Econ. Theory 144, 6.

Valletta, R., 2015. House lock and structural unemployment. Lab. Econ. 25 (C), 86-97. 